\title{
Predicted Thermal Sensation Index for the Hot Environment in the Spinning Workshop
}

\author{
Rui-Liang Yang, ${ }^{1}$ Lei Liu, ${ }^{2}$ and Yi-De Zhou ${ }^{2}$ \\ ${ }^{1}$ School of Mechanical Engineering, Tianjin Polytechnic University, Tianjin 300387, China \\ ${ }^{2}$ School of Energy and Environment, Zhongyuan University of Technology, Zhengzhou 450007, China \\ Correspondence should be addressed to Rui-Liang Yang; yangruiliang2001@sina.com
}

Received 17 March 2015; Revised 15 June 2015; Accepted 16 June 2015

Academic Editor: Jurgita Antucheviciene

Copyright (c) 2015 Rui-Liang Yang et al. This is an open access article distributed under the Creative Commons Attribution License, which permits unrestricted use, distribution, and reproduction in any medium, provided the original work is properly cited.

\begin{abstract}
The spinning workshop is the most typical cotton textile workshop in the textile mill and is characterized by the feature of high temperature all the year. To effectively evaluate the general thermal sensation of the textile worker exposed to the hot environment in the spinning workshop, a new heat index named predicted thermal sensation (PTS) index was proposed in this paper. The PTS index based on the heat balance equation can be derived by the empirical equations of air temperature and heat imbalance. A onemonth-long continuous research was carried out to investigate the actual thermal condition and judge the validity of the PTS index. Actual workshop temperatures in the spinning workshop during the measuring period were all above $32^{\circ} \mathrm{C}$, belonging to extreme hot environment. The calculated thermal sensation by the PTS index is very close to the actual thermal sensation, which means that the PTS index can accurately estimate the actual thermal sensation of the textile workers exposed to the hot environment in the spinning workshop. Compared to other indices, the PTS index can more effectively predict the mean thermal response of a large group of textile workers exposed to the hot environment in the spinning workshop.
\end{abstract}

\section{Introduction}

The spinning workshop is the most typical cotton textile workshop in the textile mill and is characterized by the feature of high temperature all the year. According to Chinese national standard "code for design of cotton spinning and weaving factory" (GB 50481-2009) [1], summer temperature of the spinning workshop should range from $30^{\circ} \mathrm{C}$ to $32^{\circ} \mathrm{C}$, much exceeding the acceptable operative temperature range from $23^{\circ} \mathrm{C}$ to $26^{\circ} \mathrm{C}$ by ISO 7730 [2]. In fact, the temperature of the spinning workshop may often be higher than $32^{\circ} \mathrm{C}$, especially in the summer. Obviously, higher temperature of the spinning workshop can decrease energy consumption and capitalized cost but results in deteriorating working conditions and poor thermal comfort. Furthermore, working in the spinning workshop with high temperature has physiological and psychological effects on workers: it reduces their productivity and increases their irritability and loss of their enthusiasm for their work [3].

Evidence about risks in a hot environment and the related health consequences have increased dramatically in the past few decades [4]. Extreme hot environment, in which the temperature is above $35^{\circ} \mathrm{C}$ for living and above $32^{\circ} \mathrm{C}$ for working [5], is prevalent in the spinning workshop. Several methods have been proposed to estimate the heat stress in an extreme hot environment. The wet-bulb globe temperature (WBGT) index [6], predicted heat strain (PHS) model [7], and the predicted mean vote (PMV) index [8] are standard methods and remain the choice by most researchers. The WBGT index is a composite temperature used to estimate the effect of temperature, humidity, and solar radiation on humans, which is regarded as the most accepted index representing the heat stress to which an individual is exposed in an industrial environment [9]. But the WGBT index should be regarded as an exploratory method, with the drawback of being longer and more difficult to undertake [6]. The most serious limitation of the WBGT index is that environments at a given level of the index are more stressful when the evaporation of sweat is restricted (by high humidity, such as the spinning workshop) than when evaporation is free [10]. Thus, it is encouraged immediately to define a new index or method instead of the WGBT index to be used 
in an industrial environment [6]. The PHS model evaluates the thermal stress in the hot climate and determinates the maximum allowable exposure time (such as Dlimtre index) with which the physiological strain is acceptable. The PHS model only considers standard subjects in good health and fit for the work they perform; it is therefore intended to be used to evaluate working conditions, and it does not predict the physiological response of individual subjects [7]. Although PHS can evaluate the exposure limit for various situations, it has a limitation when considering the cases in which humans exercise moderately [11] such as the work in the spinning workshop. The PMV index based on the heat balance of the human body can be used to predict the general thermal sensation and degree of discomfort of people exposed to moderate thermal environments, and it should be used only for values of PMV between -2 and +2 and when the main parameters are within the specified range, such as air temperature between $10^{\circ} \mathrm{C}$ and $30^{\circ} \mathrm{C}$ [2]. Except for three standard methods, there are a number of indices that have been proposed to measure the heat stress in the hot environment, such as the equivalent temperature (ET) index [12], the temperature-humidity index (THI) [13], and the environmental stress index (ESI) [14]. But these indices are mostly constructed based on several simple environmental variables, not including the personal variables and comprehensive environmental information, which makes these indices unreliable and ambiguous in the special environment such as the spinning workshop. Furthermore, most indices except the PMV index $[2,8]$ are used to evaluate the thermal condition in the hot environment instead of predicting the physiological response of individual subjects.

The textile industry plays an irreplaceable role in the Chinese economy [15] and poor workshop environment in the spinning workshop is particularly important to the health of workers [16], but there is no appropriate index used to predict the general thermal sensation of the textile worker nowadays. To effectively evaluate the general thermal sensation of the textile worker exposed to the hot environment in the spinning workshop, a heat index named predicted thermal sensation (PTS) index was proposed in this paper. The PTS index, an objective index based on the heat balance equation, can effectively predict the mean thermal response of a large group of textile workers exposed to the hot environment in the spinning workshop.

\section{Model}

The thermal balance equation of the body may be written as [17]

$$
M-W=\left(C+R+E_{\mathrm{sk}}\right)+\left(C_{\text {res }}+E_{\text {res }}\right)+S .
$$

The sensible heat loss from skin $(C+R)$, describing the heat exchanges between the clothing and the environment, is estimated by [7]

$$
\begin{aligned}
C+R=f_{\mathrm{cl}} \times\left[h_{\mathrm{cdyn}} \times\left(t_{\mathrm{cl}}-t_{a}\right)+3.96 \times 10^{-8}\right. \\
\left.\quad \times\left(t_{\mathrm{cl}}+273\right)^{4}-\left(t_{r}+273\right)^{4}\right],
\end{aligned}
$$

where the clothing area factor $f_{\mathrm{cl}}$ may be estimated from the following equation [18]:

$$
f_{\mathrm{cl}}=1+0.28 I_{\mathrm{cl}} \text {. }
$$

The dynamic convective heat exchange $h_{\text {cdyn }}$ can be estimated as [7]

$$
h_{\mathrm{cdyn}}=\max \left\{2.38\left|t_{\mathrm{sk}}-t_{o}\right|^{0.25}, 3.5+5.2 v_{a}, 8.7 v_{a}^{0.6}\right\} \text {. }
$$

The sensible heat loss from skin $(C+R)$, also describing the heat exchanges between the skin and the clothing surface, is estimated by [7]

$$
C+R=\frac{t_{\mathrm{sk}}-t_{\mathrm{cl}}}{I_{\mathrm{cldyn}}},
$$

where dynamic clothing insulation, $I_{\text {cldyn }}$, can be derived as [7]

$$
I_{\mathrm{cldyn}}=I_{\mathrm{totdyn}}-\frac{I_{\mathrm{adyn}}}{f_{\mathrm{cl}}}
$$

where

$$
\begin{aligned}
I_{\text {totdyn }} & =C_{\text {orr }, \text { tot }} \times\left(I_{\mathrm{cl}}+\frac{I_{\text {ast }}}{f_{\mathrm{cl}}}\right), \\
I_{\text {adyn }} & =C_{\text {orr }, I a} \times I_{\text {ast }} .
\end{aligned}
$$

$$
\begin{aligned}
& \text { For } I_{\mathrm{cl}} \geq 0.6 \text { clo, } \\
& C_{\text {orr,tot }}=C_{\text {orr,cl }}=e^{0.043-0.398 v_{a}+0.066 v_{a}{ }^{2}-0.378 v_{w}+0.094 v_{w}{ }^{2}} .
\end{aligned}
$$

For nude person $\left(I_{\mathrm{cl}}=0 \mathrm{clo}\right)$,

$$
C_{\text {orr,tot }}=C_{\text {orr, }, I a}=e^{-0.472 v_{a}+0.047 v_{a}^{2}-0.342 v_{w}+0.117 v_{w}{ }^{2}} .
$$

For $0 \leq I_{\mathrm{cl}} \leq 0.6 \mathrm{clo}$,

$$
C_{\text {orr }, \text { tot }}=\frac{\left(0.6-I_{\mathrm{cl}}\right) C_{\mathrm{orr}, I a}+I_{\mathrm{cl}} \times C_{\mathrm{orr}, \mathrm{cl}}}{0.6}
$$

with $C_{\text {orr,tot }}$ limited to $1, v_{a}$ limited to $3 \mathrm{~m} / \mathrm{s}$, and $v_{w}$ limited to $1.5 \mathrm{~m} / \mathrm{s}$. $I_{\text {ast }}$ is the static boundary layer thermal insulation (=0.7 clo) [18].

In the hot environment, the worker's body finally reaches steady state $[7,11]$ and the steady state mean skin temperature $t_{\text {sk }}$ can be estimated as a function of the parameters of the working situation, using the following empirical expressions [7]: 


$$
\begin{aligned}
& t_{\mathrm{sk}}= \begin{cases}t_{\mathrm{sk}, \mathrm{nu}} & \text { for } I_{\mathrm{cl}} \leq 0.2 \mathrm{clo} \\
t_{\mathrm{sk}, \mathrm{cl}} & \text { for } I_{\mathrm{cl}} \geq 0.6 \mathrm{clo} \\
t_{\mathrm{sk}, \mathrm{nu}}+2.5 \times\left(t_{\mathrm{sk}, \mathrm{cl}}-t_{\mathrm{sk}, \mathrm{nu}}\right) \times\left(I_{\mathrm{cl}}-0.2\right) & \text { for } 0.2 \mathrm{clo}<I_{\mathrm{cl}}<0.6 \mathrm{clo},\end{cases} \\
& t_{\mathrm{sk}, \mathrm{nu}}=7.19+0.064 t_{a}+0.061 t_{r}-0.348 v_{a}+0.198 p_{a}+0.616 t_{\mathrm{co}},
\end{aligned}
$$

The actual evaporation rate $E_{\text {sk }}$ is given by [19]

$$
E_{\mathrm{sk}}= \begin{cases}\lambda S_{r} & \frac{\lambda S_{r}}{E_{\max }}<0.46 \\ \lambda S_{r} \exp \left[-0.4127 \times\left(\frac{1.8 \lambda S_{r}}{E_{\max }}-0.46\right)^{1.168}\right] & 0.46 \leq \frac{\lambda S_{r}}{E_{\max }} \leq 1.7 \\ E_{\max } & \frac{\lambda S_{r}}{E_{\max }}>1.7\end{cases}
$$

where $\lambda$ is the latent heat of evaporation of sweat $=$ $657 \mathrm{~W} \cdot \mathrm{hr} / \mathrm{kg}$ at $30^{\circ} \mathrm{C}$. Sweat rate $S_{r}$ is a function of the thermoregulatory signal and can be adequately described by [19]

$$
\begin{aligned}
S_{r}= & 0.42 \\
& +0.44 \tanh \left[1.16 \times\left(0.1 t_{\mathrm{sk}}+0.9 t_{\mathrm{co}}-37.4\right)\right] .
\end{aligned}
$$

The maximum evaporative heat flow at the surface is given by [7]

$$
\begin{aligned}
& E_{\max } \\
& =\frac{0.38 \times\left(p_{\mathrm{sk}}-p_{a}\right) \times\left(2.6 C_{\text {orr,tot }}^{2}-6.5 C_{\text {orr,tot }}+4.9\right)}{16.7 \times C_{\text {orr,tot }} \times\left(I_{\mathrm{cl}}+I_{\text {ast }} / f_{\mathrm{cl}}\right)} .
\end{aligned}
$$

The saturated water vapor pressure at skin temperature $p_{\text {sk }}$ can be estimated as a function of the skin temperature $t_{\text {sk }}$.

The heat transfer from the deep body core to the skin $H$ can be expressed as [19]

$$
\begin{aligned}
H= & \left\{84+72 \times \tanh \left[1.3 \times\left(0.1 t_{\mathrm{sk}}+0.9 t_{\mathrm{co}}-37.9\right)\right]\right\} \\
& \times\left(t_{\mathrm{co}}-t_{\mathrm{sk}}\right) .
\end{aligned}
$$

For a heat balance in the body, heat flow core to skin equals heat flow skin to environment:

$$
H=E_{\mathrm{sk}}+C+R \text {. }
$$

If $t_{a}, t_{r}, p_{a}, M, v_{a}, v_{w}$, and $I_{\mathrm{cl}}$ are known, all terms in Expressions (2) (16) including $H$ and $t_{\text {co }}$ can be solved iteratively by Expressions (2) (16).

The heat flow by respiratory convective $C_{\text {res }}$ can be estimated by the following empirical expression [7]:

$$
C_{\text {res }}=0.00152 M\left(28.56+0.885 t_{a}+0.641 p_{a}\right) \text {. }
$$

The heat flow by respiratory evaporative $E_{\text {res }}$ can be estimated by the following empirical expression [7]:

$$
E_{\text {res }}=0.00127 M\left(59.34+0.53 t_{a}-11.63 p_{a}\right) .
$$

Taking Expressions (5), (12), (17), and (18) into Expression (1) yields

$$
S=M-W-\left(C+R+E_{\mathrm{sk}}\right)-\left(C_{\mathrm{res}}+E_{\mathrm{res}}\right) .
$$

The heat storage $S$ is solved as the difference between internal heat production and heat loss to the actual environment at the steady state in the hot environment for a person hypothetically kept at the empirical equations of $t_{\mathrm{sk}}, S_{r}$, and $H$. In most industrial situations including the spinning workshop, the effective mechanical power $W$ is small and can be neglected [7]. To more effectively predict the mean thermal response of a large group of textile workers exposed to the hot environment in the spinning workshop, the relationship of heat storage $S$ and TSV value was researched by linear analysis based on a large number of previous experiments. Then, a new heat index named predicted thermal sensation (PTS) index was proposed as follows:

$$
\begin{aligned}
\mathrm{PTS}= & \left(0.0025 t_{a}-0.0657\right) \\
& \times\left[M-\left(C+R+E_{\mathrm{sk}}\right)-\left(C_{\mathrm{res}}+E_{\mathrm{res}}\right)\right] .
\end{aligned}
$$

The PTS index was derived by the empirical equations of air temperature and heat imbalance between internal heat production and heat loss to the actual environment at the steady state in the hot environment. Similarly to the PMV index, the PTS index can predict the mean thermal sensation of a large group of people on the seven-point thermal sensation scale. The difference is that the PTS index was proposed to be used in the hot environment in the spinning 
TABLE 1: Anthropometric data of subjects.

\begin{tabular}{lcccc}
\hline Gender & Number & $\begin{array}{c}\text { Seniority } \\
\text { (years) }\end{array}$ & $\begin{array}{c}\text { Height } \\
(\mathrm{cm})\end{array}$ & $\begin{array}{c}\text { Weight } \\
(\mathrm{kg})\end{array}$ \\
\hline Male & 310 & $20.3 \pm 8.9^{\mathrm{a}}$ & $171.2 \pm 7.2$ & $71.1 \pm 7.5$ \\
Female & 513 & $18.1 \pm 8.6$ & $160.1 \pm 6.2$ & $60.6 \pm 7.6$ \\
Total & 823 & $19.0 \pm 8.8$ & $164.3 \pm 8.5$ & $64.5 \pm 9.1$ \\
\hline
\end{tabular}

${ }^{a}$ Standard deviation.

workshop, but the PMV index cannot be used to the hot environment in the spinning workshop due to temperature above $30^{\circ} \mathrm{C}$.

\section{Experiment}

To investigate the actual thermal condition in the spinning workshop and judge the validity of the PTS index, a onemonth-long continuous research was carried out in the spinning workshop of Zhengzhou Hongye Textile Co. Ltd., one of the largest cotton companies in Henan Province (the central part of China, the most populous province with over 103 million people). Experiments were conducted from July 1 to July 31 of 2014 in the spinning workshop with area of $4985 \mathrm{~m}^{2}$. The selected workers with years of work experience (see Table 1) were the most typical representative of Chinese textile workers. All investigated subjects recommended by the workshop director have more than 2-year work experience and were responsible for their work, which ensures that the investigated subjects fully adapt to the thermal environment of the spinning workshop. Front-line workers with $2 / 3$ of dayshifts and 1/3 of nightshifts were chosen in the survey. Atypical workers such as those with less cohesive strength or bad work were excluded from this survey to ensure that participators are typical representative. Participating workers were investigated near their workstations during the experimental process. 823 sets of data were collected in this experiment, with about 20 to 40 sets of data in one day.

The PTS index was deduced by four physical variables (temperature $t_{a}$, air velocity $v_{a}$, mean radiant temperature $t_{r}$, and relative humidity $\mathrm{RH}$ ) and three personal variables (clothing insulation $I_{\mathrm{cl}}$, activity level $M$, and walking speed $\left.v_{w}\right)$. Temperature $\left( \pm 0.5^{\circ} \mathrm{C}\right.$ for $\left.0 \sim 400^{\circ} \mathrm{C}\right)$, relative humidity $( \pm 3$ for $10 \% \sim 95 \%)$, air velocity $( \pm 0.02 \mathrm{~m} / \mathrm{s}$ for $0 \sim$ $0.99 \mathrm{~m} / \mathrm{s}, \pm 3 \%$ F.S for $1 \sim 5 \mathrm{~m} / \mathrm{s})$, and globe temperature $\left( \pm 1^{\circ} \mathrm{C}\right.$ for $0 \sim 80^{\circ} \mathrm{C}$ ) were measured by using the laboratory-grade instruments. Mean radiant temperature was calculated by temperature, air velocity, and global temperature according to ISO 7726 [20]. Measurements for workers were made in workstations where workers were known to spend their time [8]. The measuring positions were selected to be close to the participant within a distance of $0.2 \mathrm{~m}$ and at three heights $(0.1 \mathrm{~m}, 1.1 \mathrm{~m}$, and $1.7 \mathrm{~m})$. Clothing values adopted garment insulation values from ISO 9920 [18]. A time-average metabolic rate $[2,8]$ for the worker with activities was used since the worker's activity consists of a combination of work/investigation periods. Worker's miscellaneous occupational activities should be classified as "light machine work," while investigation activities should be classified as "standing, relaxed." Thus, every worker who typically spent 50 minutes out of each hour "light machine work" with metabolic rate of $128 \mathrm{~W} / \mathrm{m}^{2}$ and 10 minutes "standing, relaxed" with metabolic rate of $70 \mathrm{~W} / \mathrm{m}^{2}$ had an average metabolic rate of $128 \times$ $50 / 60+70 \times 10 / 60=118 \mathrm{~W} / \mathrm{m}^{2} \cdot p_{a}$ was estimated by the air temperature $t_{a}$ and relative humidity $\mathrm{RH}$. Due to the work characteristics of the investigated workers, the walking speed is supposed to be $0.5 \mathrm{~m} / \mathrm{s}$. Once four physical variables and three personal variables were determined, the PTS index can be calculated by Expression (20).

Analogously, the PHS model can be solved by four physical variables (temperature $t_{a}$, air velocity $v_{a}$, mean radiant temperature $t_{r}$, and relative humidity $\mathrm{RH}$ ) and five personal variables (clothing insulation $I_{\mathrm{cl}}$, activity level $M$, walking speed $v_{w}$, weight, and height) [7]. The PMV index can be obtained by temperature $t_{a}$, air velocity $v_{a}$, mean radiant temperature $t_{r}$, relative humidity $\mathrm{RH}$, clothing insulation $I_{\mathrm{cl}}$, and activity level $M[2,8]$. The WGBT index can be estimated by temperature $t_{a}$, globe temperature $t_{g}$, and relative humidity $\mathrm{RH}[6]$. Because the spinning workshop belongs to indoor hot and humid environments, solar radiation term in the ESI index can be neglected [12]. Equivalent temperature (ET) [12], the temperature-humidity index (THI) [13], and the environmental stress index (ESI) [14] were all obtained by the temperature $t_{a}$ and relative humidity $\mathrm{RH}$. The Actual Mean Vote (AMV) was obtained by thermal sensation vote recorded on the ASHRAE seven-point scale [8] during the survey.

\section{Results and Discussion}

4.1. Outdoor and Workshop Temperature during the Measuring Period. To investigate actual air temperature in the spinning workshop, a one-month-long continuous monitoring was carried out by using the laboratory-grade instruments, with eight oclock in the morning and two oclock in the afternoon, from July 1 to July 31 of 2014, and five measured points were distributed evenly in the spinning workshop. The average temperature of five measured points was used as the workshop temperature. The outdoor temperature was obtained from local meteorological records.

Figure 1 shows the outdoor temperature and workshop temperature during the measuring period (i.e., from July 1 to July 31, 2014), respectively. It can be found from Figure 1 that the workshop temperatures were all above $32^{\circ} \mathrm{C}$, exceeding the acceptable operative temperature range from $23^{\circ} \mathrm{C}$ to $26^{\circ} \mathrm{C}$ by ISO 7730 [5], required temperature range from $30^{\circ} \mathrm{C}$ to $32^{\circ} \mathrm{C}$ by $\mathrm{GB} 50481-2009$, and upper limit $30^{\circ} \mathrm{C}$ of PMV application range. Thus, the workshop environment in the spinning workshop during the measuring period belongs to extreme hot environment [5]. Due to the risks in hot environment and related health consequences, it is necessary to present an objective evaluation instead of subjective evaluation of thermal sensation for the textile worker exposed to the hot environment in the spinning workshop. The PTS index was an appropriate index to predict the thermal sensation for the textile work, which is helpful 
TABLE 2: Measured parameters around the textile worker.

\begin{tabular}{lccc}
\hline Gender & $\begin{array}{c}\text { Male } \\
(n=310)\end{array}$ & $\begin{array}{c}\text { Female } \\
(n=513)\end{array}$ & $\begin{array}{c}\text { Total } \\
(n=823)\end{array}$ \\
\hline $\begin{array}{l}\text { Temperature } t_{a}\left({ }^{\circ} \mathrm{C}\right) \\
\text { Air velocity } v_{a}(\mathrm{~m} / \mathrm{s})\end{array}$ & $33.9 \pm 1.0^{\mathrm{a}}$ & $34.1 \pm 1.0$ & $34.0 \pm 1.0$ \\
$\begin{array}{l}\text { Mean radiant } \\
\text { temperature } t_{r}\left({ }^{\circ} \mathrm{C}\right)\end{array}$ & $34.0 \pm 1.7$ & $34.0 \pm 1.8$ & $34.0 \pm 1.8$ \\
$\begin{array}{l}\text { Relative humidity } \mathrm{RH} \\
(\%)\end{array}$ & $59.2 \pm 7.6$ & $60.1 \pm 7.7$ & $59.8 \pm 7.7$ \\
$\begin{array}{l}\text { Clothing insulation } I_{\mathrm{cl}} \\
(\mathrm{clo})\end{array}$ & $0.47 \pm 0.03$ & $0.47 \pm 0.02$ & $0.47 \pm 0.03$ \\
\hline
\end{tabular}

${ }^{\mathrm{a}}$ Standard deviation.

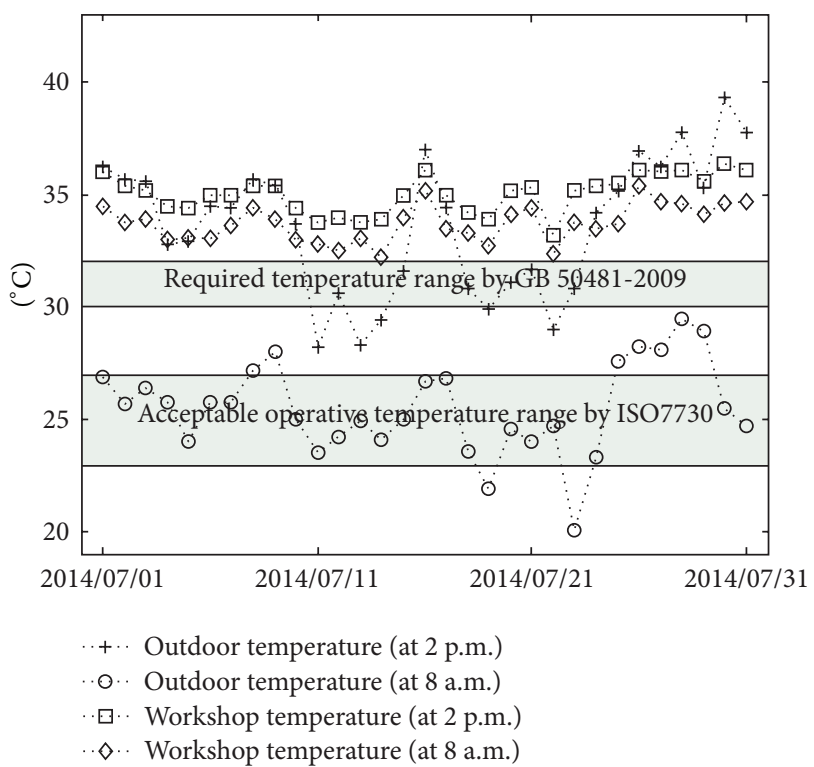

FIGURE 1: Outdoor temperature and mean workshop temperature during the measuring period.

for taking effective strategies to prevent the health risk to the worker.

\subsection{Comparison of the PTS and the Actual Thermal Sensation.}

Table 2 shows the measured parameters around the textile worker during the measuring period, which were used to derive the PTS index. Figure 2 shows the actual thermal sensation (AMV) against the PTS index. The PTS value was obtained by Expression (20), representing the calculated thermal sensation of the worker, while the AMV value was obtained by thermal sensation vote record during the survey, representing the actual thermal sensation of the worker. Most of the AMV values were 1 (denoting "slightly warm") and 2 (denoting "warm"). In Figure 2 a trend line is shown with the corresponding $R^{2}$ value $(n=823, p<0.001)$, representing AMV changes with PTS. The dotted line in Figure 2 shows PTS = AMV, so ideally all values would be on this line. The reality is that calculated thermal sensation is very close to the actual thermal sensation.

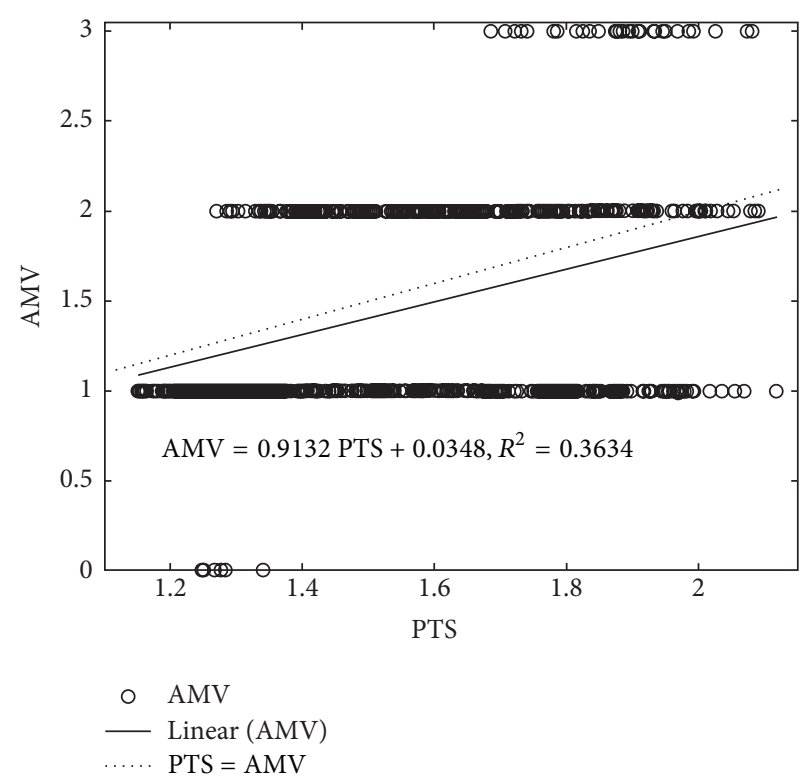

FIgURE 2: AMV versus PTS.

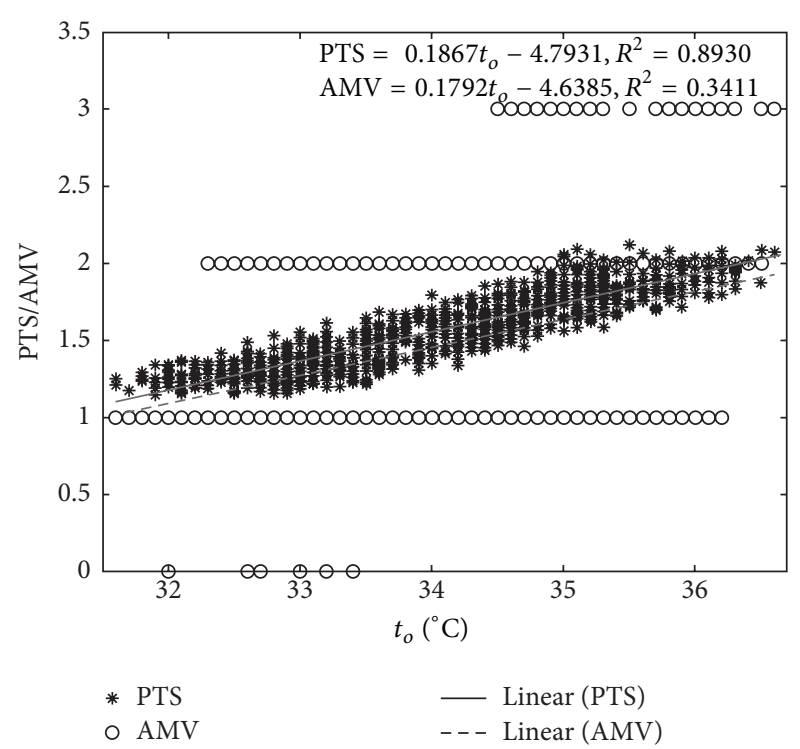

FIGURE 3: PTS/AMV versus operative temperature $t_{o}$.

Figure 3 shows the PTS/AMV against the operative temperature $t_{o}$. The operative temperature $t_{o}$ is the common temperature in the thermal research field and can be solved by the temperature $t_{a}$, air velocity $v_{a}$, and mean radiant temperature $t_{r}[2,8]$. There are two trend lines with corresponding $R^{2}$ value in Figure 3, representing PTS/AMV changes with the operative temperature $t_{o}$. Two trend lines $(n=823, p<$ $0.001)$ are very close, which means that calculated thermal sensation is very close to the actual thermal sensation. The fact that the PTS index is very close to the actual thermal sensation means that the PTS index can accurately estimate the actual thermal sensation of the textile workers in the spinning workshop. 


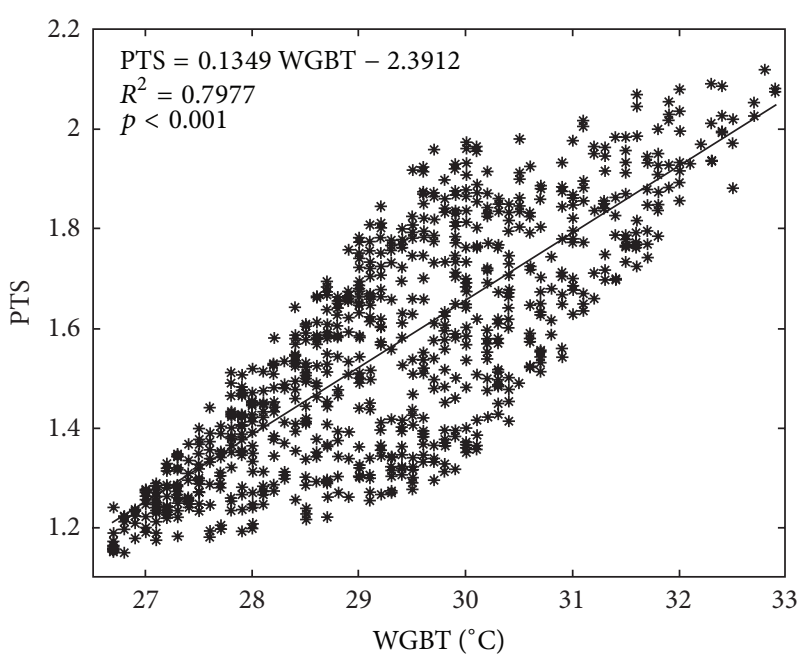

FIGURE 4: PTS versus WGBT.

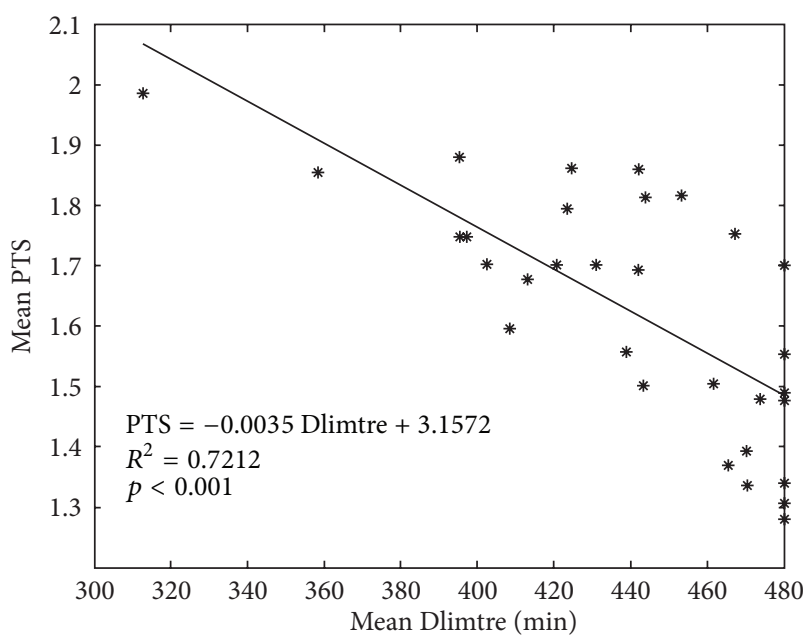

FIGURE 5: Mean PTS versus mean Dlimtre of each day during the measuring period.

4.3. Comparison of the PTS Index and Other Indices. In order to test the validity of this new index, the PTS index is compared with the commonly used indices (WBGT [6] and Dlimtre [7]) in these experiments. The WBGT index and the PHS model should be used for evaluating working conditions instead of predicting the physiological response of individual subjects. However, due to the lack of appropriate reference index, here the WGBT value and the Dlimtre index in the PHS model were used as the reference object to compare with the PTS index. The analysis between PTS and WBGT value is presented in Figure 4 for correlation. Dlimtre represents the maximum allowable exposure time for heat storage in PHS model [7], and mean Dlimtre of each day during the measuring period was calculated to compare with the mean PTS in Figure 5. The linear regression equations and the bivariate correlation results calculated by SPSS software are also shown in Figures 4 and 5. The correlations between PTS and WBGT $(n=823, p<0.001)$ and mean PTS and mean Dlimtre $(n=31, p<0.001)$ are statistically significant.

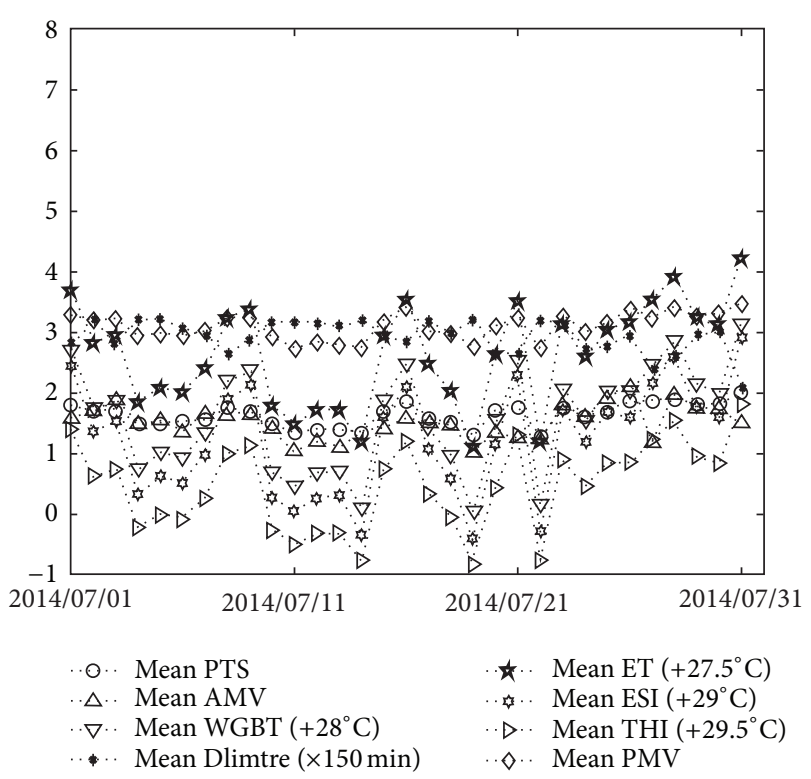

FIGURE 6: Comparison of mean PTS and other indices in each day during the measuring period. PTS: (20); AMV: thermal sensation vote; WGBT: $0.7 t_{w}+0.3 t_{g}$ [6]; ET: $0.38 t_{a}+0.63 t_{g}$ [12]; Dlimtre: maximum allowable exposure time for heat storage in PHS model [7]; PMV: PMV index [2, 8]; ESI: $0.63 t_{a}-0.03 \mathrm{RH}+0.0054\left(t_{a} \cdot \mathrm{RH}\right)-$ 0.73 [14]; THI: $t_{a}-(0.55-0.0055 \mathrm{RH}) \times\left(t_{a}-14.5\right)[13]$.

Therefore, the PTS (mean PTS) index is linearly related to the WBGT (mean Dlimtre) index.

Figure 6 shows comparison of mean PTS index and other indices in each day during the monitoring period. It can be seen from Figure 6 that the mean PTS index is much closer to the mean actual thermal sensation than other indices. Dlimtre [7], ET [12], ESI [14], and THI [13] may be used to evaluate the thermal condition in the hot environment, but they cannot be used to predict the physiological response of individual subjects. The mean PMV index much exceeded the valid PMV range of -2 to 2 in each day, meaning a large amount of thermal dissatisfied people, which is not a fact according to the AMV. Thus, compared to other indices, the PTS index can more effectively predict the mean thermal response of a large group of textile workers exposed to the hot environment in the spinning workshop.

4.4. Nonthermal Factors. Figure 7 shows AMV versus PTS of different gender (female: $n=513$; male: $n=310$ ). There are 4, 287, 199, and 23 female workers voting $0,1,2$, and 3 in the AMV inquiry, respectively, while there are $3,181,115$, and 11 male workers in the AMV inquiry. The results show that female worker and male worker have almost the same PTS and the actual thermal sensation. There are two trend lines with corresponding $R^{2}$ value in Figure 7 , representing AMV of different genders change with the PTS. Two trend lines are both very close to the line of PTS $=\mathrm{AMV}$, which means that calculated PTS values of different genders are both close to the actual thermal sensation. 


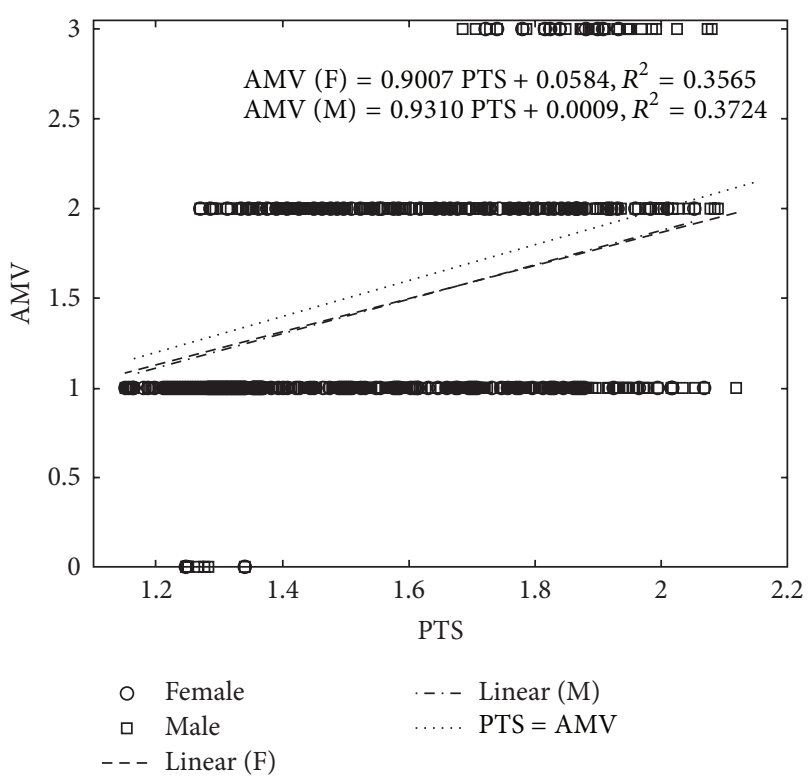

Figure 7: AMV versus PTS of different gender.

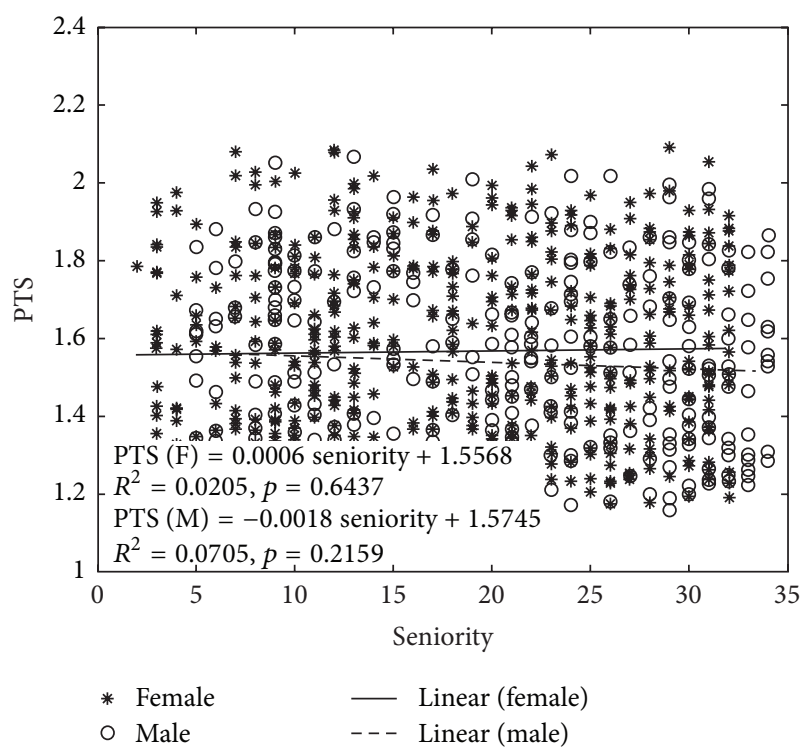

FIGURE 8: The PTS index of different gender versus seniority.

Figure 8 shows that the PTS index of the worker changes with worker's seniority. No significant differences (female: $n=513, p=0.6437$; male: $n=310, p=0.2159$ ) were observed in PTS following the seniority, which means that the thermal sensation of the textile worker has little relationship with the seniority. Reference [17] points that the young and old people are equally sensitive to cold or heat, which is confirmed with this conclusion.

\section{Conclusions}

The predicted thermal sensation (PTS) index was proposed to predict the mean thermal response of a large group of textile workers exposed to the hot environment in the spinning workshop. Actual workshop temperatures in the spinning workshop during the measuring period were all above $32^{\circ} \mathrm{C}$, exceeding the acceptable operative temperature range from $23^{\circ} \mathrm{C}$ to $26^{\circ} \mathrm{C}$ by ISO 7730 and required temperature range from $30^{\circ} \mathrm{C}$ to $32^{\circ} \mathrm{C}$ by GB 50481-2009, belonging to extreme hot environment.

Higher temperature of the cotton textile workshop may result in deteriorating working conditions and poor thermal comfort. The PTS index was an appropriate index to predict the thermal sensation for the textile work, which is helpful for taking effective strategies to prevent the health risk to the worker. Comparison of the PTS index and the AMV shows that the PTS index is very close to the actual thermal sensation, which means that the PTS index can accurately estimate the actual thermal sensation of the textile workers exposed to the hot environment in the spinning workshop. Compared to other indices, the PTS index can more effectively predict the mean thermal response of a large group of textile workers according to the ASHRAE thermal sensation scale. Furthermore, the calculated PTS values of different genders are both very close to the actual thermal sensation. No significant differences were observed in PTS following the seniority, which means that the thermal sensation of the textile worker has little relationship with the seniority.

\section{Nomenclature}

C: $\quad$ Convective heat loss from skin $\left(\mathrm{W} / \mathrm{m}^{2}\right)$

$\mathrm{C}_{\text {orr,cl }}$ : Correction for the dynamic total dry thermal insulation at or above 0.6 clo (dimensionless)

$C_{\text {orr,Ia }}$ : Correction for the dynamic total dry thermal insulation at 0 clo (dimensionless)

$C_{\text {orr,tot }}$ : Correction for the dynamic clothing insulation as a function of the dimensionless actual clothing (dimensionless)

$C_{\text {res }}$ : Heat flow by respiratory convection $\left(\mathrm{W} / \mathrm{m}^{2}\right)$

$E_{\text {max }}$ : Maximum evaporative heat flow at the skin surface $\left(\mathrm{W} / \mathrm{m}^{2}\right)$

$E_{\text {res }}$ : Heat flow by respiratory evaporative $\left(\mathrm{W} / \mathrm{m}^{2}\right)$

$E_{\mathrm{sk}}$ : Total rate of evaporative heat loss from skin $\left(\mathrm{W} / \mathrm{m}^{2}\right)$

$f_{\mathrm{cl}}$ : Clothing area factor (dimensionless)

$H$ : $\quad$ Heat transfer from the deep body core to the skin $\left(\mathrm{W} / \mathrm{m}^{2}\right)$

$h_{\text {cdyn }}$ : Dynamic convective heat exchange $\left(\mathrm{W} /\left(\mathrm{m}^{2} \cdot \mathrm{K}\right)\right)$

$I_{\text {ast }}$ : Static boundary layer thermal insulation (= 0.7 clo)

$I_{\text {adyn }}$ : Dynamic boundary layer thermal insulation

$I_{\mathrm{cl}}: \quad$ Static clothing insulation (clo)

$I_{\text {cldyn }}$ : Dynamic clothing insulation (clo)

$I_{\text {totdyn }}$ Total dynamic clothing insulation (clo) 
M: $\quad$ Activity level $\left(\mathrm{W} / \mathrm{m}^{2}\right)$

$p_{a}: \quad$ Water vapor partial pressure $(\mathrm{Pa})$

$p_{\text {sk }}:$ Saturated water vapor pressure at skin temperature $(\mathrm{Pa})$

$R: \quad$ Radiative heat loss from skin $\left(\mathrm{W} / \mathrm{m}^{2}\right)$

RH: Relative humidity (\%)

$S: \quad$ Heat storage $\left(\mathrm{W} / \mathrm{m}^{2}\right)$

$S_{r}: \quad$ Sweat rate $\left(\mathrm{kg} /\left(\mathrm{m}^{2} \cdot \mathrm{hr}\right)\right)$

$t_{a}: \quad$ Air temperature $\left({ }^{\circ} \mathrm{C}\right)$

$t_{\mathrm{cl}}: \quad$ Clothing surface temperature $\left({ }^{\circ} \mathrm{C}\right)$

$t_{\mathrm{co}}:$ Core temperature $\left({ }^{\circ} \mathrm{C}\right)$

$t_{g}: \quad$ Globe temperature $\left({ }^{\circ} \mathrm{C}\right)$

$t_{o}: \quad$ Operative temperature $\left({ }^{\circ} \mathrm{C}\right)$

$t_{r}: \quad$ Mean radiant temperature $\left({ }^{\circ} \mathrm{C}\right)$

$t_{\mathrm{sk}}: \quad$ Temperature of skin compartment $\left({ }^{\circ} \mathrm{C}\right)$

$t_{\mathrm{sk}, \mathrm{nu}}$ : Steady state mean skin temperature for nude subject $\left({ }^{\circ} \mathrm{C}\right)$

$t_{\mathrm{sk}, \mathrm{cl}}$ : Steady state mean skin temperature for clothed subject $\left({ }^{\circ} \mathrm{C}\right)$

$t_{w}: \quad$ Wet-bulb temperature $\left({ }^{\circ} \mathrm{C}\right)$

$v_{a}: \quad$ Air velocity $(\mathrm{m} / \mathrm{s})$

$v_{w}: \quad$ Walking speed $(\mathrm{m} / \mathrm{s})$

$W: \quad$ Effective mechanical power $\left(\mathrm{W} / \mathrm{m}^{2}\right)$

$\lambda$ : Latent heat of evaporation of sweat, $657 \mathrm{~W} \cdot \mathrm{hr} / \mathrm{kg}$ at $30^{\circ} \mathrm{C}(\mathrm{W} \cdot \mathrm{hr} / \mathrm{kg})$.

\section{Conflict of Interests}

The authors declare that there is no conflict of interests regarding the publication of this paper.

\section{Acknowledgments}

This research was supported by the NSFC (the Natural Science Foundation of China) no. 51208527 and Funding Scheme for Young Teachers of Higher School in Henan Province (2012GGJS-124).

\section{References}

[1] GB 50481, "Code for design of cotton design spinning and weaving factory," 2009.

[2] ISO, "Ergonomics of the thermal environment-analytical determination and interpretation of thermal comfort using calculation of the PMV and PPD indices and local thermal comfort criteria," ISO 7730, 2005.

[3] J. Zhao, N. Zhu, and S. Lu, "Productivity model in hot and humid environment based on heat tolerance time analysis," Building and Environment, vol. 44, no. 11, pp. 2202-2207, 2009.

[4] M. Ilangkumaran, M. Karthikeyan, T. Ramachandran, M. Boopathiraja, and B. Kirubakaran, "Risk analysis and warning rate of hot environment for foundry industry using hybrid MCDM technique," Safety Science, vol. 72, pp. 133-143, 2015.

[5] Z. Tian, N. Zhu, G. Zheng, and H. Wei, "Experimental study on physiological and psychological effects of heat acclimatization in extreme hot environments," Building and Environment, vol. 46, no. 10, pp. 2033-2041, 2011.
[6] ISO, "Hot environments-estimation of the heat stress on working man, based on the WBGT-index (wet bulb globe temperature)," ISO 7243, 1989.

[7] ISO, "Ergonomics of the thermal environment-analytical determination and interpretation of heat stress using calculation of the predicted heat strain," ISO 7933, 2004.

[8] ANSI/ASHRAE Standard 55, "Thermal environment conditions for human occupancy," 2013.

[9] R. Kralikovaa, H. Sokolovaa, and E. Wessely, "Thermal environment evaluation according to indices in industrial workplaces," Procedia Engineering, vol. 69, pp. 158-167, 2014.

[10] G. M. Budd, "Wet-bulb globe temperature (WBGT)-its history and its limitations," Journal of Science and Medicine in Sport, vol. 11, no. 1, pp. 20-32, 2008.

[11] R. Ooka, Y. Minami, T. Sakoi, K. Tsuzuki, and H. B. Rijal, "Improvement of the sweating model in 2-node model and its application to thermal safety for hot environment," Building and Environment, vol. 45, no. 7, pp. 1565-1573, 2010.

[12] C. Liang, G. Zheng, N. Zhu, Z. Tian, S. Lu, and Y. Chen, "A new environmental heat stress index for indoor hot and humid environments based on Cox regression," Building and Environment, vol. 46, no. 12, pp. 2472-2479, 2011.

[13] J. Unger, "Comparisons of urban and rural bioclimatological conditions in the case of a Central-European city," International Journal of Biometeorology, vol. 43, no. 3, pp. 139-144, 1999.

[14] D. S. Moran, K. B. Pandolf, Y. Shapiro et al., "An environmental stress index (ESI) as a substitute for the wet bulb globe temperature (WBGT)," Journal of Thermal Biology, vol. 26, no. 4-5, pp. 427-431, 2001.

[15] J. Ruan and X. Zhang, "“Flying geese" in China: The textile and apparel industry's pattern of migration," Journal of Asian Economics, vol. 34, pp. 79-91, 2014.

[16] R. Yang, L. Liu, and Z. Long, "Research on workshop environment in the textile company using analytic hierarchy process," Energy Education Science and Technology, vol. 33, no. 3, pp. 15811594,2015

[17] ASHRE Handbook-Fundamental, American Society of Heating, Refrigerating and Air-Conditioning Engine, 2009.

[18] ISO, "Estimation of thermal insulation and water vapour resistance of a clothing ensemble," ISO 9920, 2007.

[19] C. H. Wyndham and A. R. Atkins, "A physiological scheme and mathematical model of temperature regulation in man," Pflügers Archiv European Journal of Physiology, vol. 303, no. 1, pp. 14-30, 1968.

[20] International Organization for Standardization (ISO), ISO 2276, Ergonomics of the Thermal Environment-Instruments for Measuring Physical Quantities, International Organization for Standardization (ISO), London, UK, 1998. 


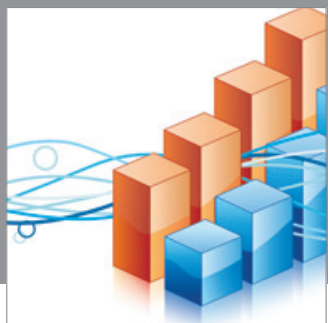

Advances in

Operations Research

mansans

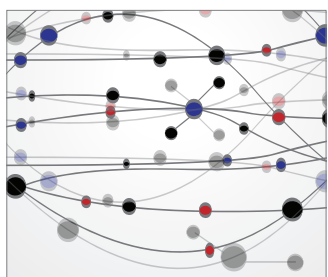

The Scientific World Journal
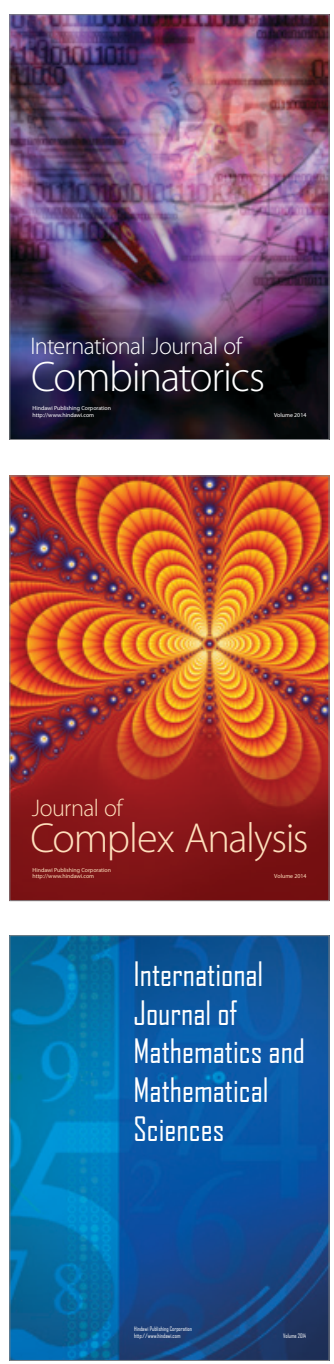
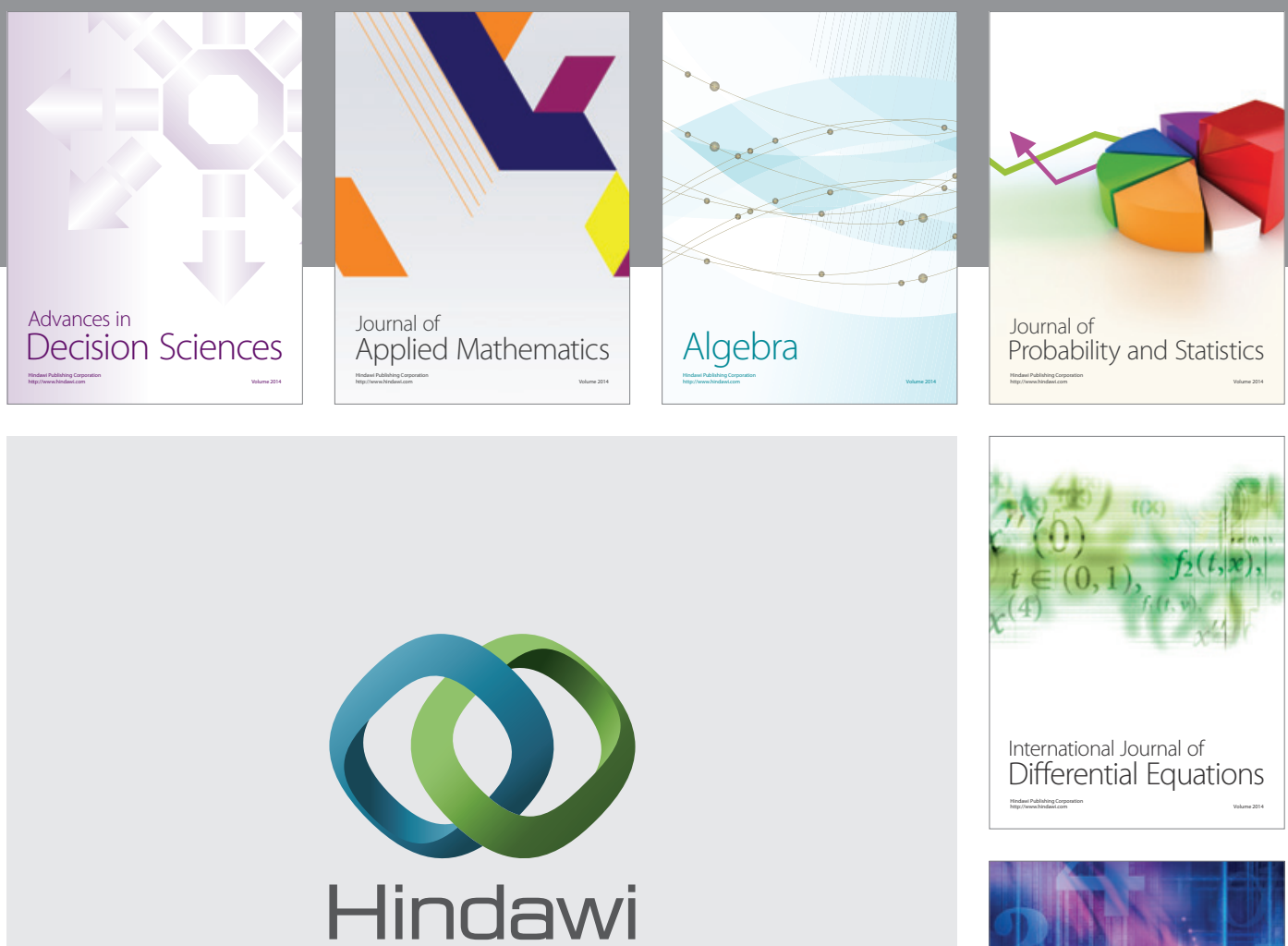

Submit your manuscripts at http://www.hindawi.com
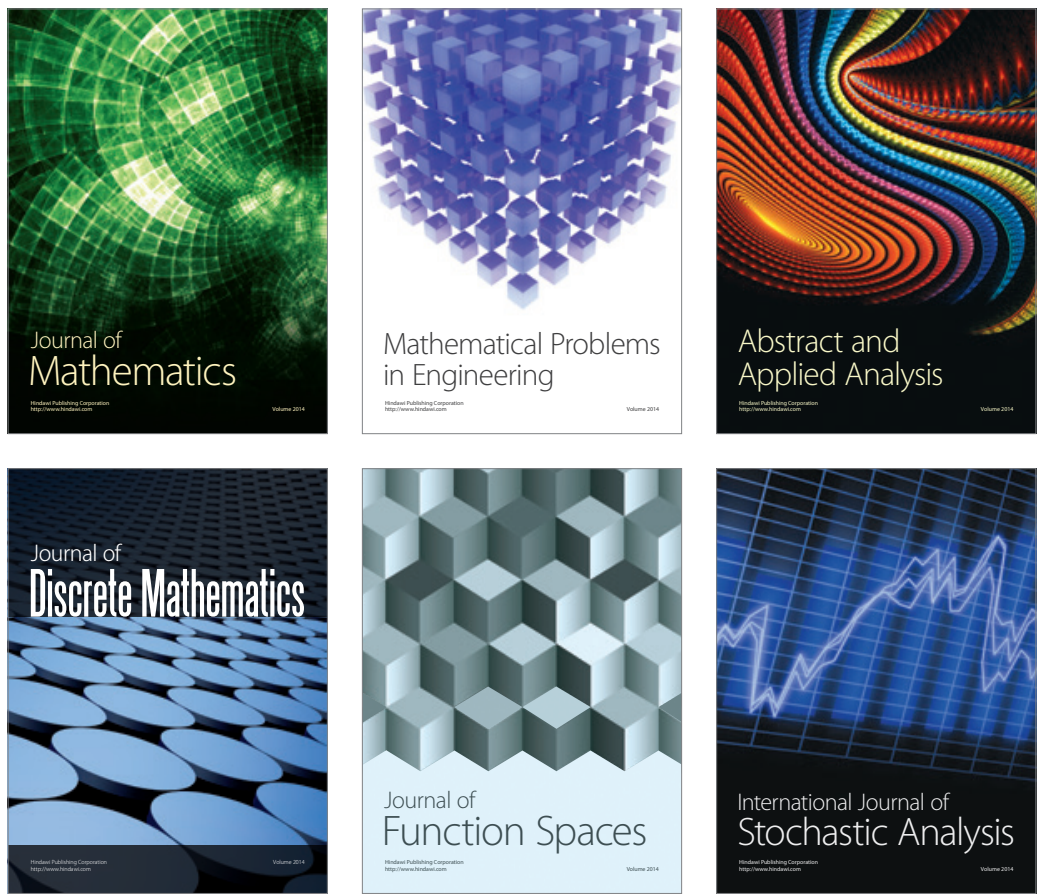

Journal of

Function Spaces

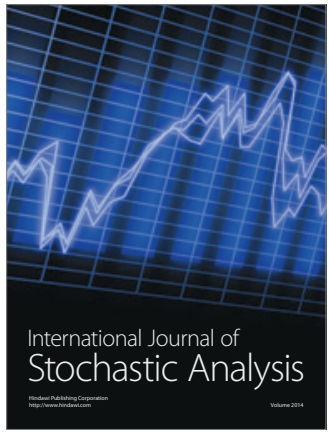

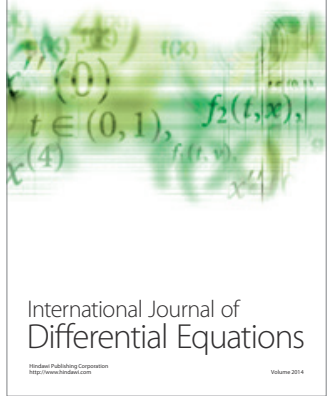
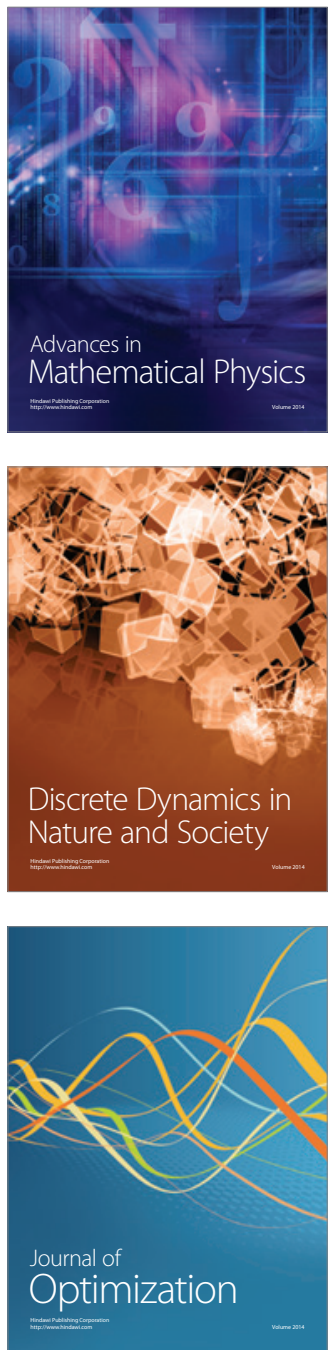